Revista Mídia e Cotidiano

Artigo Seção Temática

Volume 13, Número 1, abril de 2019

Submetido em: 12/02/2019

Aprovado em: 24/04/2019

\title{
DISCURSO E HEGEMONIA NO JORNAL TRIBUNA DO NORTE: A GESTÃO PRIVADA DE SERVIÇOS PÚBLICOS E A CONSTRUÇÃO DE SENTIDOS SOBRE AS ORGANIZAÇÕES SOCIAIS (OSs).
}

\section{SPEECH AND HEGEMONY IN THE NORTH TRIBUNE JOURNAL: THE PRIVATE MANAGEMENT OF PUBLIC SERVICES AND THE CONSTRUCTION OF MEANINGS ABOUT SOCIAL ORGANIZATIONS (OSS).}

\author{
Luciana Miranda COSTA ${ }^{1}$; João Paulo Rodrigo Hermes da SILVA ${ }^{2}$
}

\section{Resumo}

A partir da articulação de processos linguísticos e ideológicos, esse artigo busca distinguir e analisar o discurso da grande imprensa na produção de sentidos acerca da gestão privada de Organizações Sociais (OSs) em serviços públicos de saúde de Natal, no Rio Grande do Norte. A argumentação ampara-se na Análise do Discurso de linha francesa, bem como nos subsídios de Volóchinov (2017), Foucault (1996) e Moraes (2010) para analisar as representações ideológicas e hegemônicas, de viés neoliberal, em matérias veiculadas pelo jornal Tribuna do Norte, principal publicação do RN.

Palavras-chave: Comunicação, Análise do Discurso; Tribuna do Norte, SUS, OSs.

\begin{abstract}
From the articulation of linguistic and ideological processes, this paper seeks to distinguish and analyze the discourse of the mainstream press in the production of meanings about the private management of Social Organizations (OSs) in public health services in Natal, Rio Grande do Norte. The argumentation is based on French Discourse Analysis, as well as on the subsidies of Volóchinov (2017), Foucault (1996) and Moraes (2010) to analyze the ideological and hegemonic representations of neoliberal bias in news stories published by the newspaper Tribuna do Norte, the main publication of the $\mathrm{RN}$.
\end{abstract}

Keywords: Communication, Speech analysis, Tribuna do Norte, SUS, Oss.

\footnotetext{
${ }^{1}$ Professora do Programa de Pós-graduação em Estudos da Mídia da Universidade Federal do Rio Grande do Norte (UFRN) e do Programa de Pós-graduação em Comunicação, Cultura e Amazônia da Universidade Federal do Pará. E-mail: lmirandaeua@ hotmail.com

${ }^{2}$ Mestrando pelo Programa de Pós-graduação em Estudos da Mídia da Universidade Federal do Rio Grande do Norte (UFRN). E-mail: joaodasilva74@yahoo.com.br
} 
Introdução

Tendo como base o discurso da comunicação sindical frente às políticas de gestão privada do SUS (Sistema Único de Saúde) em Natal, entre 2010 e 2012, este artigo, sob um recorte analítico específico, buscou identificar como são construídos os efeitos de sentido no discurso do jornal potiguar Tribuna do Norte, sobre a gestão privada de serviços públicos por meio de Organizações Sociais (OSs). O periódico é considerado o principal instrumento de comunicação impresso do $\mathrm{RN}$, por ser o mais antigo, contabilizando 69 anos de existência ${ }^{3}$, e por possuir a maior circulação no estado, com tiragem média de 9.000 exemplares aos domingos e 7.000 exemplares nos dias úteis (terça a sábado $)^{4}$.

Sob um enfoque qualitativo, duas matérias publicadas no site do veículo foram escolhidas: Os caminhos para o bom desempenho (LIRA, 2011) e As ferramentas para a superação de obstáculos (TRIBUNA DO NORTE, 2011), publicadas nos dias 10 e 28 de agosto de 2011, respectivamente. Entre 2010 e 2012, identificamos diversas matérias no site do jornal Tribuna do Norte que tratam da implantação de Organizações Sociais na gestão de serviços de saúde em Natal. A maioria é composta de registros factuais (20 notícias), que abordam o início da terceirização com a inauguração de UPAs e AMEs, o anúncio de contratos com OSs, a abertura de inquéritos e disputas judiciais entre a Prefeitura e o MPE, denúncias de superfaturamento e suspensão de contratos. Neste universo, nos chamou a atenção duas matérias não relacionadas diretamente a registros factuais sobre o tema, mas que tratavam da importância de modernos instrumentos de gestão disponíveis ao Estado e citavam as Organizações Sociais como exemplo, inclusive a tentativa com o município de Natal. Os dois textos em questão foram veiculados em agosto de 2011, três meses após uma decisão judicial que proibiu a Prefeitura de realizar novos contratos com $\mathrm{OSs}^{5}$. A escolha deste recorte se deu em razão de julgarmos

\footnotetext{
${ }^{3}$ ASSEMBLEIA comemora 69 anos de fundação da Tribuna do Norte. Tribuna do Norte. Natal, 26 mar. 2019. Disponível em: <http://www.tribunadonorte.com.br/noticia/assembleia-comemora-69-anos-defundaa-a-o-da-tribuna-do-norte/443072> Acesso em 12 de abril de 2019.

4 MÍDIA Kit - Tribuna do Norte 2018. Tribuna do Norte. Natal, 2018. Disponível em: <http://www.tribunadonorte.com.br/tmp/downloads/midia_kit_2018.pdf>. Acesso em 14 de abr. de 2019.

${ }^{5}$ Em 05 de maio de 2011, o juiz Airton Pinheiro atendeu ao pedido do Ministério Público Estadual e proibiu a Prefeitura de Natal de celebrar novos contratos com Organizações Sociais para gestão de serviços do
} 


\section{míDiA

representativas as duas matérias porque estas buscaram apresentar uma substancialidade sócio-histórica para tais instrumentos de gestão, ao contrário dos registros factuais, sobretudo em um momento de questionamento público das Organizações Sociais.

O ano de 2011 é significativo porque a Prefeitura de Natal encontrava-se em meio a uma disputa judicial para prosseguir com a implantação de Organizações Sociais (OSs) na gestão de Unidades de Pronto-atendimento (UPAs) e Ambulatórios Médicos Especializados (AMEs). A terceirização na gestão de serviços de saúde teve início com a aprovação da Lei Municipal 6.108, de 02 de junho de 2010, e com a contratação, no mesmo período, do Instituto Pernambucano de Assistência Social (IPAS) para gerir a UPA Dr. Ruy Pereira. O contrato, feito pela Prefeitura de Natal sem licitação, passou a ser investigado através de um inquérito civil do Ministério Público Estadual, em razão de inconstitucionalidade na lei que autorizou a terceirização. Em dezembro do mesmo ano, o IPAS desistiu do contrato, mesmo tendo vencido a licitação feita neste período. A Prefeitura, então, declarou vencedora a Associação Marca, a segunda colocada no processo licitatório da UPA, que desde novembro de 2010 já administrava as AMEs em Natal.

Em 2012, após vários desdobramentos judiciais e investigações, esta experiência de administração passaria a ser alvo de uma investigação do Ministério Público Estadual (MPE), nomeada de Operação Assepsia ${ }^{6}$, que apurou um esquema de contratos fraudulentos e superfaturados na Secretaria de Saúde de Natal, através das Organizações Sociais. O inquérito resultou na condenação de gestores, empresários e da então prefeita, Micarla de Sousa.

Delineado este breve contexto, iremos apresentar a seguir os principais conceitos que embasarão nossa análise sobre o corpus selecionado.

SUS, em razão de irregularidades na contratação. Disponível em: http://www.tribunadonorte.com.br/noticia/juiz-proibe-novos-contratos-com-oss/180502. Acesso em 24 de abr.de 2019.

${ }^{6}$ A Justiça Federal do RN condenou nove pessoas na Operação Assepsia, em 2016, dentro de um esquema de fraude em processo licitatório, lavagem de dinheiro, desvio de verba, corrupção passiva e associação criminosa, gerida a partir da Prefeitura de Natal em procedimento que incidia sobre terceirização do serviço de saúde. Mais informações em https://www.jfrn.jus.br/noticia.xhtml?idNoticia=10707. Acesso em 24 de abr.de 2019. 


\section{míDiA

\section{Discurso e Ideologia}

Embates econômicos, sociais, políticos e ideológicos se expressam em todas as esferas das atividades do homem, seja no trabalho, na comunicação, na arte, na cultura ou no discurso. Este último se refere à compreensão da língua em uso pelos homens, seus aspectos sociais, ideológicos e históricos, no domínio da produção de sentidos e na constituição da realidade. Ao falar, não produzimos apenas mensagens a serem decodificadas, mas efeitos de sentidos, construídos sob determinadas condições históricas, que deixam marcas e vestígios. Orlandi (1999) observa que a linguagem não pode ser vista de maneira fria, neutra e sem vida, mas precisa ser compreendida como uma mediação entre o homem e a realidade; como interação social. Assim, "a linguagem é linguagem porque faz sentido; e a linguagem só faz sentido porque se inscreve na história" (ORLANDI, 1999, p. 25).

Colaborando com estas considerações iniciais, Brandão (2004) afirma que em nossa linguagem há um distanciamento entre a coisa representada e o signo que a representa. É nesta distância, nesta fissura, que reside o ideológico. Chauí (1984) observa que a ideologia organiza-se como um sistema lógico e coerente de representações (ideias e valores) e de normas ou regras (de conduta) (CHAUÍ, 1984, p.113). Bourdieu (1998, p. 14), por sua vez, assinala que "o efeito propriamente ideológico consiste precisamente na imposição de sistemas de classificação políticos sob a aparência legítima de taxionomias filosóficas, religiosas, jurídicas, etc". Os sistemas simbólicos devem a sua força ao fato de as relações de força que nelas se exprimem só se manifestarem neles em forma irreconhecível de relações de sentido (deslocação) (BOURDIEU, 1998, p. 14).

Ao pensarmos em discurso, portanto, não tratamos da transmissão de uma informação ou de uma mensagem, como encontrado no esquema básico sobre comunicação: emissor - mensagem/canal - receptor. $\mathrm{O}$ discurso não é isso. $\mathrm{O}$ discurso é a via expressa por onde trafegam a língua e a ideologia, em direção à produção de sentidos por e para os sujeitos. E considerando que os sujeitos são fundamentalmente ideológicos e que não há discursos sem sujeitos, tudo o que é dito está marcado ideologicamente, porque "o discurso é o lugar do trabalho da língua e da ideologia" (ORLANDI, 1999, p. $38)$. 
[...] o sistema da língua é o mesmo para o materialista e para o idealista, para o revolucionário e para o reacionário, para o que dispõe de um conhecimento dado e para o que não dispõe. Isso não resulta que eles terão o mesmo discurso: a língua aparece como a base comum de processos discursivos diferenciados. (PÊCHEUX, 1988, p. 81)

Portanto, no estudo sobre o discurso, a linguagem é colocada na relação entre sujeitos e sentidos, que são afetados pela língua em uso e pela história, num complexo processo de significação. Tudo o que é dito não reflete apenas o lugar e as condições em que é dito, mas também outros lugares e condições daquilo que já foi dito e que vai continuar a sê-lo. É o interdiscurso acionando a memória discursiva, outros sujeitos e contextos, para significar. Não há discurso possível fora das relações sociais, alheio a toda historicidade, desvinculado de suas condições de produção. Não se pode encarar o signo como algo inerte, a língua como um sistema abstrato; tudo é vivo, dinâmico e dialético, porque "a linguagem é lugar de conflito, de confronto ideológico, não podendo ser estudada fora da sociedade, uma vez que os processos que a constituem são históricosociais" (BRANDÃO, 2004, p. 11).

É por isso que o mundo da linguagem, conforme defende Pinto (1999), é o mundo do ideológico e do poder. Em qualquer processo de comunicação social, o poder está em jogo. E esta noção de poder de um discurso designa necessariamente seus efeitos de sentido dentro de uma textura determinada de relações sociais. Como discurso é efeito de sentido no mecanismo da interlocução, “o ideológico é uma dimensão necessária de todos os discursos, responsável pela produção de qualquer sentido social [...]” (PINTO, 1999, p. 42). Assim, na conjugação entre a língua e a história para produzir sentidos, o discurso constitui o lugar onde a ideologia se manifesta, através da materialidade da linguagem.

Ainda que a língua em si seja a mesma para todo mundo, indiferente às ideologias ou às políticas de privatização do SUS, por exemplo, o discurso não é. Nós utilizamos a língua de acordo com as nossas posições políticas, sociais e ideológicas. Os sentidos não são determinados pela língua, mas sim pela relação estabelecida entre as formações discursivas, dentro de um processo de disputa entre formações ideológicas. O conceito de formação discursiva é assim definido por Foucault: 
No caso em que se puder descrever, entre um certo número de enunciados, semelhante sistema de dispersão, e no caso em que entre os objetos, os tipos de enunciação, os conceitos, as escolhas temáticas, se puder definir uma regularidade (uma ordem, correlações, posições e funcionamentos, transformações), diremos, por convenção, que se trata de uma formação discursiva [...]. (2012, p. 47)

A partir da noção foucaultiana, Pêcheux desenvolveu seu próprio conceito, alinhando sua compreensão às dinâmicas e aos conflitos de um determinado contexto sócio-histórico. Nesta perspectiva, uma formação discursiva é "[...] aquilo que, numa formação ideológica dada, isto é, a partir de uma posição dada numa conjuntura dada, determinada pelo estado da luta de classes, determina o que pode e deve ser dito [... $]^{7,}$ (PÊCHEUX, 1988, p. 160-161). Por formação ideológica, Pêcheux (1988) entende um complexo conjunto de atitudes e representações que não são nem individuais nem universais, mas dizem respeito, direta ou indiretamente, às posições políticas e econômicas de onde se fala ou escreve e têm a ver com as relações de poder que se estabelecem entre os indivíduos. Assim, cada formação ideológica pode compreender várias formações discursivas em interação. Deste modo, o lugar do qual falamos é determinante para a produção dos sentidos. É a partir desta compreensão que a Análise do Discurso vai buscar um olhar sócio-histórico, assinaladamente ideológico, sobre o poder simbólico ${ }^{8}$ estabelecido no ato de significar e significar-se. Um esforço para encontrar os caminhos dos discursos na constituição e na permanência das representações sociais.

\section{Mídia e Hegemonia}

Estudar a mídia é algo imperativo. Ela está ao nosso redor e compreende todas as dimensões de nossa experiência geral com os outros e com o mundo, sob aspectos sociais,

\footnotetext{
${ }^{7}$ De acordo com Marx e Engels (2007) as classes sociais caracterizam-se pelo conjunto de suas condições básicas de existência, não pelo que os homens creem ou possam crer que são, mas pelo que realmente são no decorrer de sua vida. Assim, a classe é determinada pela posição que os indivíduos ocupam na organização econômica da sociedade, na divisão do trabalho e na reprodução da vida social.

${ }^{8}$ Segundo Bourdieu, "o poder simbólico é, com efeito, esse poder invisível o qual só pode ser exercido com a cumplicidade daqueles que não querem saber que lhe estão sujeitos ou mesmo que o exercem" (1998, p.09). O poder simbólico é um poder de construção da realidade, estando os diversos grupos sociais envoltos em uma luta simbólica para impor uma definição do mundo mais adequada aos seus interesses.
} 


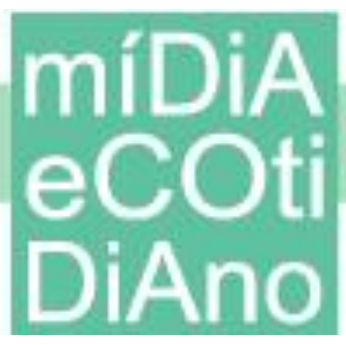

culturais, políticos e econômicos. Estudar a mídia é dissecar seu poder de gerar significados na estruturação da vida cotidiana. "Nossa mídia é onipresente, diária, uma dimensão essencial de nossa experiência contemporânea. É impossível escapar à presença, à representação da mídia” (SILVERSTONE, 2005, p. 12).

Neste sentido, é preciso entender a mídia como um processo em curso, permanente. Um processo histórico que atravessa a forma como interpretamos a realidade social, uma mediação que nos permite modificar e sermos modificados, nesta constante transformação de significados. Isto implica reconhecer, também, que este é um processo político e econômico, fundamentalmente. E é assim porque está relacionado ao poder que determinados grupos sociais adquirem ao controlar e gerir os veículos de comunicação, na produção e na distribuição das mensagens. Esta compreensão é importante porque tem a ver com as representações midiáticas e sua capacidade para filtrar e interferir nas realidades, em um exercício contínuo de manutenção do senso comum. "Qualquer meio de comunicação dominante, com mensagens mais ou menos consistentes, isto é, ideológicas, provavelmente terá um efeito naqueles que o consomem" (SILVERSTONE, 2005, p. 177).

Este efeito de poder na formação e representação das mensagens na sociedade, a exemplo do que pode fazer e faz o jornalismo dos grandes veículos, expressa o poder da mídia em criar e sustentar significados; de persuadir, endossar e reforçar as ideias que compõem os interesses de determinados grupos sociais. Neste sentido, numa sociedade, com interesses políticos e econômicos historicamente conflitantes, os meios de comunicação desempenham um papel decisivo. Exercem uma força destacada na formação, consolidação e manutenção da hegemonia dominante.

Aqui, pensamos o conceito de hegemonia nas perspectivas gramscianas de Dênis de Moraes (2010) e de Vito Giannotti (2014), cuja concepção é de uma visão de mundo feita de valores políticos, culturais e morais, com base em uma força social organizada que assegura e expande este olhar, através de um forte consenso traduzido em ação. De um ponto de vista gramsciano, consenso (convencimento) e força (coerção) andam juntos. 
Nas palavras de Giannotti, "ter a hegemonia é dar a direção. A direção político-ideológica à sociedade" (2014, p. 14).

E é na realização desta finalidade que os instrumentos privados de hegemonia, a exemplo da imprensa, exercem muitas vezes a função de "caixas de ressonância de posições presentes nas pelejas ideológico-culturais" (MORAES, 2010, p.59). Isto é assim porque, conforme sustentam nossas referências, os meios de comunicação se constituem como instrumentos de ideologia para disseminar e contribuir para manter o consenso. Colocam o que deve ou não ser considerado digno de atenção e quais as visões da realidade a serem consideradas, frente aos produtos simbólicos. $\mathrm{Na}$ trilha desta compreensão, Moraes (2010) afirma ainda que a hegemonia atravessa e condiciona os meios de comunicação, ao mesmo tempo em que também se solidifica por meio deles, interferindo na produção simbólica que ajusta o imaginário social e as disputas de sentido e de poder na sociedade. Funciona desta forma porque é dentro do universo da comunicação que "se esculpem os contornos da ordem hegemônica, seus tentáculos ideológicos, suas hierarquias, suas expansões contínuas no bojo da mercantilização generalizada dos bens simbólicos" (MORAES, 2010, p. 68).

Não é à toa que a comunicação ocupa um papel central na política, seja através de livros e jornais na derrubada de monarquias absolutistas no século XVIII ou na invasão de um país do Oriente Médio por uma potência estrangeira ${ }^{9}$, apoiada em um discurso antiterror reproduzido nos telejornais. Como observa Giannotti, não há poder sem comunicação, pois “a mídia é uma nova realidade que divulga, propagandeia, sustenta ou abala e derruba um governo, um sistema, um regime” (2014, p. 33). Nesta perspectiva, a chamada neutralidade jornalística não é somente um mito, mas também uma impossibilidade histórica.

\footnotetext{
${ }^{9}$ O presidente dos Estados Unidos, George W. Bush, ordenou a invasão do Iraque em 2003, no rastro dos atentados da Al Qaeda em 11 de setembro de 2001. Sob o discurso de combater o terrorismo e de eliminar supostas armas de destruição em massa do ditador Saddam Hussein, a invasão durou 8 anos e custou a vida de 115,5 mil civis iraquianos e de 4.483 militares americanos. Meses após o início da guerra, as razões apresentadas revelaram-se, conforme noticiou a própria imprensa, uma falácia. Disponível em https://acervo.estadao.com.br/noticias/acervo,com-justificativa-falsa-iraque-era-invadido-ha-10anos,8951,0.htm. Acesso em 22 de abr. de 2019.
} 
O Privado no SUS

O Sistema Único de Saúde (SUS) é uma das conquistas dos trabalhadores brasileiros e tem entre seus princípios a Universalidade, a Integralidade e a Equidade no acesso aos serviços de saúde. Entretanto, este é um direito que sobrevive em meio a constantes alterações em sua estrutura, através de políticas governamentais que levam ao subfinanciamento do SUS e à privatização do setor, contrapondo-se ao Artigo 196 da vigente Constituição Federal, promulgada em 1988, quando a saúde pública foi consolidada como Direito de Todos e Dever do Estado.

Apesar deste princípio básico, a presença da iniciativa privada no SUS já é introduzida no ato de seu nascimento, quando o mesmo texto constitucional, no Artigo $199, \S 1^{\circ}$, permite a participação do setor privado de forma complementar. Este processo neoliberal $^{10}$ sobre o SUS ganhou corpo nos anos 1990, com as medidas do governo Fernando Collor (1990-1992) para enxugar as obrigações do Estado. Mas o aprofundamento se deu com o governo Fernando H. Cardoso (1995-2003), quando em 1995, o então ministro da Administração Federal e Reforma do Estado, Luiz Carlos Bresser Pereira, elaborou o Plano Diretor da Reforma do Estado. De acordo com Rezende (2008), o governo FHC justificava que as funções do Estado deveriam ser de coordenar e financiar as políticas públicas, e não de executá-las. Além disso, "defendia que 'nem tudo que é público é estatal' e afirmava que 'devemos socializar com a iniciativa privada a responsabilidade de diminuir as mazelas provocadas pelo mercado .'” (2008, p. 26-27).

Com a aprovação da Reforma, educação, saúde, cultura e produção de ciência e tecnologia passam a fazer parte de um setor não exclusivo do Estado, criando uma distinção no conceito de público e estatal. Assim, a saúde, mesmo pública, não seria necessariamente estatal, podendo ser executada e gerida pela iniciativa privada. Neste

\footnotetext{
${ }^{10}$ De acordo com Anderson (1995), as ideias neoliberais nasceram logo após a II Guerra Mundial, na região da Europa e da América do Norte, onde imperava o capitalismo. "Foi uma reação teórica e política veemente contra o Estado intervencionista e de bem-estar. [...] um ataque apaixonado contra qualquer limitação dos mecanismos de mercado por parte do Estado [...]" (ANDERSON, 1995, p. 09). A proposta neoliberal busca reduzir a atuação do Estado, estabelecendo austeridade nos gastos sociais, privatização de serviços públicos e ruptura com o poder dos sindicatos. A Sociedade de Mont Pèlerin, fundada em 1947 na Suíça por um grupo de intelectuais, a exemplo de Friedrich Hayek, Milton Friedman, Ludwig Von Mises, entre outros, é a base histórica do neoliberalismo.
} 
contexto, são criadas as Organizações Sociais, os Contratos de Gestão e o Programa Nacional de Publicização, com a Lei 9.637, de 1998, e as Organizações da Sociedade Civil de Interesse Público (OSCIPS), através da Lei 9.790, de 1999. Paralelo a esse arcabouço jurídico que criou os instrumentos de terceirização dos serviços públicos, Fernando Henrique Cardoso também aprovou a Lei de Responsabilidade Fiscal (Lei Complementar 101/2000), que limitava os gastos com pessoal, aprofundando o subfinanciamento dos serviços, ao mesmo tempo em que reforçava a contratação por meio de empresas terceirizadas. (REZENDE, 2008)

A lei que instituiu as Organizações Sociais, conforme aponta Rezende, concebia que as OSs poderiam "contratar funcionários sem concurso público, adquirir bens e serviços sem processo licitatório e não prestar contas a órgãos de controle internos e externos da administração pública, porque estas são consideradas 'atribuições privativas do Conselho de Administração'.” (2008, p. 29). Na prática, a lei estabeleceu as garantias e condições para a programação do "estado mínimo no país", conforme preconizava o Plano Diretor da Reforma do Aparelho do Estado. Por este caminho, serviços públicos produzidos pelo Estado, como a saúde pública, puderam ser terceirizados e privatizados e as responsabilidades exclusivas da União passaram a ser transferidas para entidades privadas. Estas, inclusive, se tornaram aptas a "dispor de poupança, bens, patrimônio, créditos e servidores públicos para administrar seus próprios interesses e, ainda assim, serem declaradas como 'entidades de interesse social e utilidade pública', para todos os efeitos legais" (REZENDE, 2008, p. 29).

Este foi o caminho para repassar a gestão do SUS a formas de administração não estatal, como as Organizações Sociais (OSs), as Fundações Estatais de Direito Privado e a Empresa Brasileira de Serviços Hospitalares (EBSERH). Estas últimas consagradas sob os governos do PT (Partido dos Trabalhadores), nos governos de Lula da Silva (20032011) e Dilma Rousseff (2011-2016), ampliadas pela terceirização intensiva do governo de Michel Temer (2016-2018) ${ }^{11}$.

\footnotetext{
11 A EBSERH é uma empresa pública de direito privado, instituída para administrar os Hospitais Universitários (HUs). Em seu último dia de mandato, em 31 de dezembro de 2010, o então presidente Lula assinou a Medida Provisória 520/10, que criou a Empresa Brasileira de Serviços Hospitalares S.A. (EBSERH). No ano seguinte, a medida foi transformada em proposta de lei, aprovada pelo Congresso e
} 
Um dos argumentos dos governos era o de que as atividades não exclusivas do Estado poderiam ser transferidas ao setor privado, sem fins lucrativos, sob a justificativa de parceria e modernização do Estado, já que esta movimentação resultaria em melhores serviços à população, aumento da eficiência, melhor atendimento e menor custo. Mas o que realmente ocorreu com as terceirizações estabelecidas na Lei das OSs, segundo Rezende, foi "uma transferência, pelo Estado, de suas unidades hospitalares, prédios, móveis, equipamentos, recursos públicos e, muitas vezes, pessoal para a iniciativa privada" (REZENDE, 2008, p. 33).

Deste modo, a partir das contribuições expostas acima, apresentaremos como são construídos os efeitos de sentido do discurso do jornal Tribuna do Norte, enquanto veículo de imprensa hegemônico, a respeito das políticas de gestão privada nos serviços públicos em Natal.

\section{O discurso do jornal Tribuna do Norte}

Com o objetivo de distinguir e analisar os discursos e a construção de sentidos sobre as Organizações Sociais (OSs) na gestão privada de serviços de saúde pública, selecionamos, sob um enfoque qualitativo, duas matérias representativas, relacionadas ao assunto no site do veículo Tribuna do Norte, o principal jornal do RN. Os textos foram publicados em agosto de 2011, em meio às tentativas da Prefeitura de Natal de prosseguir com a administração de OSs nas Unidades de Pronto-atendimento (UPAs) e nos Ambulatórios Médicos Especializados (AMEs) do município.

Para analisar os dois textos selecionados, iremos utilizar algumas das contribuições de Volóchinov (2017), Foucault (1996) e Pêcheux (1988). Como já visto, os sentidos não existem em si mesmos, mas apenas quando são determinados pelas ideologias em disputa no processo sócio-histórico, no qual as palavras são produzidas. Para Volóchinov (2017), a palavra é um fenômeno ideológico por excelência e pode

sancionada em 15 de dezembro de 2011 pela presidenta Dilma Rousseff (Lei 12.550/2011). Em 31 de março de 2017, o presidente Michel Temer sancionou a lei 13.429/2017, que regulamentou a terceirização irrestrita, para todas as atividades das empresas, inclusive a chamada atividade-fim, aquela para a qual a empresa foi criada. A lei permite que a contratação terceirizada possa ocorrer sem restrições também na administração pública, aprofundando as formas de privatização nos serviços públicos. 
assumir qualquer função ideológica. Nela, habita uma onipresença social. A palavra participa de toda interação e contato entre as pessoas, seja no trabalho, em situações do dia a dia ou nas relações políticas. Sendo assim, é na palavra que "se realizam os inúmeros fios ideológicos que penetram todas as áreas da comunicação social" (VOLÓCHINOV, 2017, p. 106). Mesmo as palavras mais simples do nosso cotidiano, dentro do processo de intercâmbio social, nos abordam repletas de sentidos, produzindo significações em nós e para nós.

Na primeira matéria analisada, publicada pelo veículo Tribuna do Norte, Os caminhos para o bom desempenho (LIRA, 2011), o texto apresenta uma narrativa na qual expõe alguns instrumentos de gestão criados a partir da Reforma do Estado, de 1995, sob o governo de Fernando Henrique Cardoso, que "visavam modificar o funcionamento do poder público, de burocrático para o social". Destaca também, no primeiro e segundo parágrafos, que estes instrumentos são considerados "fundamentais para que uma instituição pública consiga bons índices de desempenho" e que têm como objetivo "aliar o resultado e a eficiência". A segunda matéria do jornal analisada, As ferramentas para a superação de obstáculos (TRIBUNA DO NORTE, 2011), acompanha o mesmo caminho narrativo a respeito da Reforma do Estado e dos princípios estabelecidos por ela, destacando como objetivos principais dos instrumentos de gestão, a "eficiência" e "serviços públicos de qualidade ao menor custo possível".

Pêcheux (1988) coloca que os sentidos das palavras derivam das formações discursivas nas quais elas se inscrevem e que, assim, as palavras mudam seus sentidos de acordo com as posições ideológicas daqueles que as empregam. Portanto, a mesma palavra pode adquirir sentidos diferentes dependendo da formação discursiva na qual esteja inserida.

Nos textos em análise, as expressões "desempenho", "resultado", "eficiência" e "ao menor custo possível", numa interdiscursividade sócio-histórica relacionada às mudanças do Estado nos anos 1990, inscrevem-se em uma formação discursiva filiada a uma formação ideológica neoliberal do mundo. Aqui, os sentidos atribuídos às referidas 
palavras remetem a concepções da lógica de funcionamento capitalista ${ }^{12}$, da iniciativa privada, com produtividade e metas a serem cumpridas.

Para concretizar os princípios norteadores da gestão pública eficiência, resultado, funcionamento orientado para o cidadão - os gestores precisam lançar mão de uma série de medidas, chamadas instrumentos ou ferramentas de gestão e consideradas fundamentais para que uma instituição pública consiga bons índices de desempenho. Essas ferramentas foram quase todas pensadas em conjunto com a chamada Reforma do Estado, iniciada no Brasil, em 1995, e visavam modificar o funcionamento do poder público, de burocrático para social. (LIRA, 2011)

Realizada a reforma gerencial do Estado e estabelecidos os princípios da administração pública a partir daquela data, passou a ser necessário definir instrumentos para se atingir os principais objetivos: eficiência, serviços públicos de qualidade ao menor custo possível. Alguns desses instrumentos, em voga até hoje, já haviam sido definidos na Constituição de 1988. Outros foram possibilitados pela reforma. De qualquer forma, são instrumentos que a cada dia ganham mais espaço dentro da administração e tentam dar excelência às políticas públicas. (TRIBUNA DO NORTE, 2011)

A expressão "ao menor custo possível”, inclusive, insere-se na mesma cadeia lexical de "otimização de recursos", buscando resignificar o problema da qualidade dos serviços apenas como uma demanda de gestão, e não de subfinanciamento. Anuncia-se, assim, o discurso de que os caminhos para o bom desenvolvimento do setor público passam pelo modelo da iniciativa privada, cuja orientação atende a necessidades de mercado. Conforme observa Volóchinov, nos marcos da história e das relações sociais, "ao realizar-se no processo da comunicação social, todo signo ideológico, inclusive o signo verbal, é determinado pelo horizonte social de uma época e de um grupo social" (2017, p. 110).

Ainda no segundo parágrafo de Os caminhos para o bom desempenho (LIRA, 2011), o texto jornalístico afirma que alguns dos instrumentos e ferramentas de gestão,

\footnotetext{
12 Conforme Lessa e Tonet (2011), o Capitalismo é um sistema socioeconômico baseado na propriedade privada dos meios de produção (terras, fábricas, bancos), no qual os produtos do trabalho assalariado são apropriados pelos capitalistas (proprietários dos meios) e transformados em mercadorias que devem ser vendidas. O sistema capitalista intensificou a produção, mas aprofundou a concentração de riqueza e a desigualdade social.
} 
principalmente aqueles que implicam na "diminuição da presença direta do poder público, são polêmicos e rechaçados por alguns setores da sociedade". Neste trecho, há um silenciamento das vozes dissonantes, aqui classificadas como "alguns setores da sociedade", que sequer são identificados.

Como a oferta de serviços aos cidadãos e o funcionamento da máquina pública com qualidade aliada ao menor gasto possível foram eleitos como prioridades, os instrumentos que favorecem a participação social, a avaliação constante e o acompanhamento dos resultados. Independente do nome que se dê a tais instrumentos - e com a expansão das tecnologias da informação e da internet eles são cada vez mais diversos - o objetivo é aliar o resultado e a eficiência. Alguns são amplamente difundidos e aprovados. Outros, principalmente os que implicam uma diminuição da presença direta do poder público, são polêmicos e rechaçados por alguns setores da sociedade. (LIRA, 2011)

Quando dizemos algo, fazemos de uma forma, e não de outra. Deste modo, ao escolhermos uma forma de dizer, excluímos outras possibilidades de dizê-lo. Para Orlandi (2002), o silêncio é uma prática de processos de significação que remete ao caráter de incompletude da linguagem, no qual todo dizer estabelece um não-dizer e apaga outros sentidos possíveis. No caso em questão, são apagadas as vozes de sentidos indesejáveis sobre os instrumentos de gestão que implicam na "diminuição da presença direta do poder público". Situação semelhante pode ser identificada na outra matéria do jornal, As ferramentas para a superação de obstáculos, no trecho que se refere à abertura dos serviços públicos para empresas e organizações: "Há quem veja nisso uma diminuição da força do Estado e formas de terceirização e privatização disfarçadas" (TRIBUNA DO NORTE, 2011). Em "há quem veja nisso", identificamos uma minimização dos espaços para vozes divergentes e o estabelecimento da dúvida sobre a terceirização e a privatização.

Porém, o mesmo não acontece com quem está na ordem do discurso. Para Foucault (1996), o discurso é o lugar onde se exerce o poder, onde se selecionam os sujeitos que falam. E só pode falar quem tem poder, sendo a fala a realizadora deste. Nas matérias analisadas, quem exerce o poder de fala é a diretora do Centro de Ciências Sociais Aplicadas da UFRN, Arlete Duarte. Nos textos veiculados pelo jornal, ela é a voz 
da autoridade institucional que fala sobre os instrumentos de gestão e participação da sociedade na realização dos serviços. Entre as ouvidorias, audiências públicas e agências reguladoras, também são apresentadas “as organizações sociais (OSs) e organizações da sociedade civil com interesse público (Oscip's), os contratos de gestão para contratualizar e pactuar, etc. Isso tudo inaugura uma série de funções novas para o Estado" (TRIBUNA DO NORTE, 2011).

As alterações a que se refere Duarte, que inauguram "funções novas para o Estado", entre elas as OSs e Oscip's, por nós aqui destacadas, estão no bojo das mudanças operadas pela Reforma do Estado de Fernando Henrique Cardoso, em 1995. Conforme já exposto por Rezende (2008), as leis que instituíram a gestão privada de serviços públicos através de OSs e Oscip's, sob a ótica neoliberal de modernização, favoreceram o caminho da minimização do papel do poder público. Assim, entre as "funções novas do Estado", estão a de ser menor e a de não executar determinados serviços, abrindo espaços para a privatização.

Se por um lado, a voz da autoridade institucional tem poder de fala e o exerce a partir do discurso, que se mantém controlado, selecionado e organizado para dominar o acontecimento, as vozes dissonantes são excluídas para assegurar a manutenção do poder do discurso instituído. Segundo Brandão (2004), saber e poder convergem para uma articulação no espaço do discurso, "pois quem fala, fala de algum lugar, a partir de um direito reconhecido institucionalmente. Esse discurso, que passa por verdadeiro, que veicula saber (o saber institucional), é gerador de poder [...]”. (p. 37). Nesta mesma perspectiva, a exclusão de sujeitos diferentes da ordem do discurso é realizada por alguns mecanismos que Foucault (1996) nomeou de interdição de linguagem, separação e rejeição. Buscaremos visualizá-los no seguinte trecho da matéria em análise:

Um dos instrumentos mais contestados é a descentralização dos serviços do Estado através das Organizações Sociais, Organizações da Sociedade Civil de Interesse Público, Parcerias Público-privadas, entre outras. Setores contrários ao aumento das parcerias entre o setor público estatal e a iniciativa privada e o terceiro setor classificam essas iniciativas como "privatização", "terceirização", etc. Sem entrar no mérito, o fato é que nos últimos anos esses instrumentos têm sido largamente utilizados, independente da inclinação ideológica do governo do momento. Todos eles diminuem a presença direta do poder público na oferta de serviços. (LIRA, 2011) 
Neste fragmento, o texto nomeia de descentralização (sem aspas) a realização de serviços do Estado por Organizações Sociais, Organizações da Sociedade Civil de Interesse Público e Parcerias Público-privadas. Por outro lado, mais uma vez sem identificar quem são os "setores contrários" a esta política. O mesmo texto põe entre aspas as palavras "privatização" e "terceirização", formas com as quais as vozes silenciadas classificam o "aumento das parcerias entre o setor público estatal e a iniciativa privada e o terceiro setor”. Mais do que apenas apontar citações, a ausência ou a presença das aspas indicam, aqui, quem está e quem não está na ordem do discurso, o que é e o que não é permitido neste discurso. Temos a definição do que é verdadeiro (descentralização, sem aspas) sendo instituída em oposição ao que é falso (privatização e terceirização, com aspas). Ao estabelecer uma demarcação de entendimentos com o uso das aspas, a matéria veiculada no site do jornal separa e rejeita a classificação de "privatização" e "terceirização", determinando que as vozes dos "setores contrários" terão suas falas interditadas e serão afastadas.

Ainda no fragmento citado acima, sobre OSs, Oscip's e PPPs, o texto afirma que "o fato é que nos últimos anos esses instrumentos têm sido largamente utilizados, independente da inclinação ideológica do governo do momento". As expressões "o fato é", "largamente utilizados" e "independente da inclinação ideológica" são empregadas de forma a construir uma imagem positiva e inquestionável sobre tais instrumentos. Deste modo, a narrativa busca um efeito de sentido de silenciamento das diferenças, como se as ferramentas de gestão dos serviços estivessem acima das disputas ideológicas na sociedade. Mais à frente, em outra parte da matéria, o texto aponta que as Organizações Sociais (OSs) são usadas na gestão de Unidades de Pronto-atendimento (UPAs) em vários estados, como São Paulo, Minas Gerais e Pernambuco.

No mesmo trecho, também destaca que na capital potiguar "houve uma tentativa com a UPA de Pajuçara, mas uma decisão judicial afastou a possibilidade. Nesses casos, o Estado delega a função de administrar. Os defensores do SUS, por exemplo, são contra a ideia" (LIRA, 2011). Ao assinalar que as OSs são usadas em "vários estados", o texto reforça o sentido produzido pela expressão "largamente utilizados", na procura por 


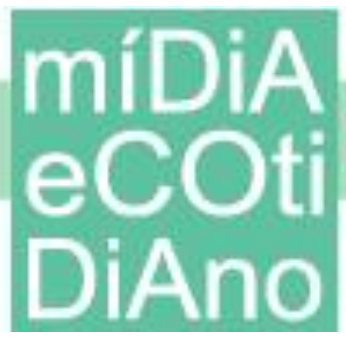

desautorizar os questionamentos a esta forma de administração não estatal. A matéria diz ainda que uma decisão judicial "afastou a possibilidade" de Natal ter uma OS na gestão de uma UPA, mas silencia sobre as razões, interditando outros sentidos indesejáveis sobre a imagem que se pretende construir em torno do setor privado. Já a palavra "contra" atribui um sentido negativo "aos defensores do SUS", uma vez que estes não aceitam que o Estado delegue, ou seja, divida funções. Ao dizer isto, não se explicita outros sentidos possíveis e praticamente apagam-se as vozes que falam em privatização.

Temos desta forma, a partir de uma compreensão neoliberal presente no discurso da imprensa, a construção de sentidos positivos sobre a abertura dos serviços do Estado, no caso o SUS, para organizações do setor privado. Na manutenção deste ponto de vista, as vozes dos sujeitos discordantes são interditadas e desautorizadas, com o objetivo de reforçar as posições ideológicas que veem na privatização e na lógica de funcionamento capitalista, os caminhos para o bom desempenho dos serviços públicos.

\section{Considerações Finais}

$\mathrm{Na}$ articulação entre a língua e a história, são produzidos os sentidos que atravessam a todos nós, constituindo a realidade e por ela sendo constituídos. Assim, quando a manchete de uma notícia ou a chamada de um telejornal, por exemplo, inicia destacando que uma greve de professores deixou mais de 50 mil alunos sem aula, tem-se um efeito de sentido que pode conduzir o leitor ou telespectador à conclusão de que as greves prejudicam a população. O mesmo pode acontecer quando as matérias de um jornal contribuem para reforçar um discurso, cujas formações discursivas e ideológicas se filiam ao neoliberalismo, para defender a "eficiência" da gestão privada sobre o setor público, já que "o poder público não funciona".

Esse processo ideológico atravessa uma série de procedimentos discursivos para produzir sentidos, através dos quais buscamos identificar a construção simbólica de um poder que se manifesta no discurso, por meio do uso social da língua. Nos textos do jornal Tribuna do Norte que analisamos, foi possível identificar como o poder de fala dos sujeitos inscritos em formações discursivas neoliberais, findavam por interditar vozes de 


\section{míDiA

sujeitos divergentes, produzindo e endossando sentidos de caráter hegemônico, como a ideia da ineficiência estatal e a necessidade de abertura ao setor privado.

Nesta perspectiva, os sentidos construídos pelo discurso da imprensa contribuíram para a representação de uma realidade na qual as OSs expressam a superioridade da gestão privada sobre a administração pública. Algo anunciado, por exemplo, nos títulos das matérias que, conjugados à argumentação dos textos, apontam que "os caminhos para o bom desempenho" e "as ferramentas para a superação de obstáculos" nos serviços públicos de saúde passam pela modernização e eficiência vistas no modelo privado.

\section{Referências Bibliográficas}

ANDERSON, Perry. In: SADER, Emir \& GENTILI, Pablo (orgs.). Pós-neoliberalismo: as políticas sociais e o Estado democrático. Rio de Janeiro: Paz e Terra, 1995, p. 9-23.

BOURDIEU, Pierre. O Poder Simbólico. Rio de Janeiro: Bertrand Brasil, 1998.

BRANDÃO, Helena H. Nagamine. Introdução à Análise do Discurso. Campinas, SP: Ed. Unicamp, 2004.

CHAUÍ, M. O que é ideologia. $15^{\mathrm{a}}$ ed. São Paulo: Brasiliense, 1984.

FOUCAULT, Michel. A arqueologia do saber. Trad. Luiz Felipe Baeta Neves. 8. ed. Rio de Janeiro: Forense Universitária, 2012.

Edições Loyola, 1996.

, Michel. A ordem do discurso. Trad. Laura Fraga de Almeida Sampaio. São Paulo:

GIANNOTTI, Vito. Comunicação dos Trabalhadores e Hegemonia. São Paulo: Editora Fundação Perseu Abramo, 2014.

LESSA, Sérgio; TONET, Ivo. Introdução à filosofia de Marx. 2. ed. São Paulo: Editora Expressão Popular, 2011

LIRA, Isaac. Os caminhos para o bom desempenho. TRIBUNA DO NORTE, 2011. Disponível em: $\quad<\mathrm{http} / / / w w w . t r i b u n a d o n o r t e . c o m . b r / n o t i c i a s / o s-c a m i n h o s-p a r a-o-b o m-$ desempenho/191725>. Acesso em: 4 de julho de 2018.

MARX, Karl; ENGELS, Friedrich. Manifesto Comunista e Princípios do Comunismo. Trad. Diego Siqueira. São Paulo: Editora Sundermann, 2007.

MORAES, Dênis de. Comunicação, hegemonia e contra-hegemonia: a contribuição teórica de Gramsci. Porto Alegre: Revista Debates, v.4, n.1, p. 54-77, jan.-jun. 2010.

ORLANDI, Eni Puccinelli. Análise do Discurso - princípios e procedimentos. Campinas, SP: Pontes, 1999.

Eni Pulcinelli. As formas do silêncio: nos movimentos dos sentidos. 5. ed. Campinas, SP: Editora da UNICAMP, 2002. 
PÊCHEUX, M. Semântica e Discurso: uma crítica à afirmação do óbvio. Trad. E. P. Orlandi e outros. Campinas, SP: Ed. Unicamp, 1988.

PINTO, Milton José. Comunicação e Discurso: introdução à análise de discursos. São Paulo: Editora Hacker, 1999.

REZENDE, Conceição Aparecida Pereira. O modelo de gestão do SUS e as ameaças do projeto neoliberal. Rio de Janeiro: Rede Sirius/Adufrj-SSind, 2008.

SILVERSTONE, Roger. Por Que Estudar A Mídia? São Paulo: Loyola, 2005.

TRIBUNA DO NORTE. As ferramentas para a superação de obstáculos. 2011. Disponível em: $\quad<\mathrm{http} / / / \mathrm{www}$.tribunadonorte.com.br/noticias/as-ferramentas-para-a-superacao-deobstaculos/193792>. Acesso em: 4 de julho de 2018.

VOLÓCHINOV, Valentim. Marxismo e filosofia da linguagem: problemas fundamentais do método sociológico na ciência da linguagem. Trad. Sheila Grillo e Ekaterina V. Américo. São Paulo: Editora 34, 2017. 